\title{
QUESTÃO AGRÁRIA, MOVIMENTOS SOCIAIS E EDUCAÇÃO DO CAMPO: conquistas, desafios e retrocessos
}

\author{
Domingos Rodrigues da Trindade* \\ Orlando Santana Costa**
}

\begin{abstract}
Resumo: Este artigo busca discutir a tríade Questão Agrária, Movimentos Sociais e Educação do Campo, em uma perspectiva analítica conceitual ao modo de produção camponesa frente ao capitalismo agrário, tendo como pressuposto a relevância dos movimentos sociais no processo histórico contra-hegemônico. Utilizou-se como base para coleta de dados a pesquisa bibliográfica de caráter qualitativo a partir de estudos de autores que discutem o tema e buscam destacar a importância de uma reforma agrária popular para diminuir as desigualdades sociais no campo e por uma Educação do Campo libertadora que priorize a cultura camponesa. Assim, destacamos que a luta dos movimentos sociais não é apenas por terra, mas também por um projeto popular de Educação do Campo que incorpore o conhecimento dos camponeses à reflexão acerca do trabalho e das lutas sociais.
\end{abstract}

Palavras-chave: Reforma Agrária. Movimentos Sociais. Educação do Campo.

\section{AGRARIAN QUESTION, SOCIAL MOVEMENTS AND FIELD EDUCATION: achievements, challenges and setbacks}

\begin{abstract}
This article seeks to discuss the triad Agrarian Question, Social Movements and Field Education, from a conceptual analytical perspective to the peasant mode of production in the face of agrarian capitalism, based on the assumption of the relevance of social movements in the counterhegemonic historical process. The bibliographical research of a qualitative nature was used as a basis for data collection from studies of authors who discuss the theme and seek to highlight the importance of a popular agrarian reform to reduce social inequalities in the field and by a Liberating Field Education that prioritize peasant culture. Thus, we stress that the struggle of social movements is not only by land, but also by a popular Field Education project that incorporates the knowledge of the peasants to reflect on work and social struggles.
\end{abstract}

Keywords: Agrarian Reform. Social movements. Field Education.

Submissão 30-09-18 Aceite 12-12-18

\section{INTRODUÇÃO}

O objetivo principal deste trabalho é apresentar uma reflexão acerca da questão agrária no Brasil, da luta dos movimentos sociais e da Educação do Campo, destacando suas intrínsecas relações. Compreendemos que a questão agrária vista na perspectiva da maneira como a sociedade organiza o uso, a posse e a propriedade dos bens da natureza está relativamente ligada às questões econômicas, sociais, políticas, ambientais e educacionais. Nesse sentido, a luta dos movimentos sociais do campo, em especial do Movimento dos Trabalhadores Rurais Sem Terra (MST), em defesa da valorização do

\footnotetext{
* Possui graduação em Licenciatura Plena em Pedagogia pela Universidade do Estado da Bahia (2000), mestrado (2011) e doutorado (2015) em Educação pela Universidade de Brasília. Professor adjunto do DEPARTAMENTO DE EDUCAÇÃO, CAMPUS XII/UNEB. É vinculado ao Núcleo de Estudos, Pesquisa e Extensão Educacional Paulo Freire/NEPE.

** Graduado em Pedagogia (2015) e especialista em Educação do Campo (2018) pela UNIVERSIDADE DO ESTADO DA BAHIA - UNEB - DEDC CAMPUS XII - GUANAMBI - BA. É vinculado ao Núcleo de Estudos, Pesquisa e Extensão Educacional Paulo Freire/NEPE pela UNEB DEDC Campus XII.
} 
modo de vida camponês em suas especificidades e por direito à terra, por meio da reforma agrária, não é uma luta fácil, tendo em vista o padrão cultural dominante que foi construído em nossa sociedade desde as lutas do período colonial no Brasil, entre colonizador e colonizados, até os dias atuais.

Os conflitos entre classes sociais sempre estiveram presentes durante o percurso da história da humanidade, pois desde o período primitivo, quando se organizavam para caçar, pescar e plantar, já existiam tribos ou clãs que guerreavam entre si em busca de objetivos comuns ou diferentes. Os vários conflitos e lutas de classes impulsionaram o surgimento dos movimentos sociais. Este termo foi criado por Lorenz Von Stein, em 1840, a partir do mundo urbano-industrial; o termo passou a ser usado na contemporaneidade como sinônimo de mobilizações, rebeliões, revoltas, protestos, greves, grupos de interesses, ações coletivas, dentre outros (SILVA, 2001).

A luta dos movimentos sociais impulsiona a conquista por mais direitos trabalhistas, tendo em vista que essa luta é histórica, ampla e complexa; não se encerra aqui, mas abre um leque para discussões em torno dessa temática. Apesar de termos uma diversidade de estudos sobre os movimentos sociais, como os desenvolvidos por FERNANDES, 2001; GOHN, 2008; DESMARAIS, 2013; MELUCCI, 1989; ainda não se tem na atualidade um conceito exato para os movimentos sociais. No mundo cada vez mais globalizado em que vivemos, mudam-se as relações sociais de conflitos e, logicamente, as esferas e meios de produção se alteram interligados aos problemas culturais, de identidade, cidadania, educação e trabalho.

Desde a chegada dos portugueses ao Brasil e após mais de 500 anos de luta pela igualdade de acesso à terra, adentramos no século XXI lutando para garantir direitos. Em nosso país, desde as capitanias hereditárias até os latifúndios atuais, a estrutura de concentração de terra e de poder, atrelado aos meios de produção, vem sendo mantida com um alto índice de desigualdade social e uma má distribuição de renda que escraviza os mais pobres.

Muito se discute a importância da reforma agrária no Brasil, mas existem diversas formas de obtenção de terra pelo Estado para sua redistribuição. A forma mais usada, indo de encontro à reforma agrária de mercado, é a desapropriação, que estabelece metas e critérios para locação e repartição da terra comprada pelo governo na mão do fazendeiro/proprietário, e o Estado, em seguida, organiza um projeto para redistribuição das terras para as famílias de camponeses.

No Brasil, tratar de projetos políticos referentes à reforma agrária é algo recente 
se comparado ao processo de acumulação de terras controladas pelo empresariado agroindustrial originário do sistema de colonização escravocrata. A luta por reforma agrária ganhou força nos últimos anos com o surgimento, principalmente, do MST, em 1984, e as organizações sindicais que tinham como objetivo principal democratizar o acesso de todos à propriedade da terra.

O MST nasce, assim, da luta da classe trabalhadora camponesa como forma de resistência, enfrentamento e oposição ao modelo de produção capitalista agrário instaurado no campo durante o período militar. O MST lutava, principalmente, nesse período, contra a expropriação de terras e a exploração do desenvolvimento capitalista no meio rural, tendo como objetivos a luta por acesso à terra, a luta por reforma agrária e a luta por mudanças sociais na estrutura formativa latifundiária do país, propondo mudanças na matriz de produção do capitalista agrário por uma matriz mais agroecológica e sustentável para garantia da soberania alimentar.

É de fundamental importância compreendermos que a luta pela democratização de acesso à terra surge com o latifúndio, sendo assim é necessário separar a luta pela terra da luta pela reforma agrária. Dessa forma, observa-se que a luta pela terra é uma disputa política ampla entre povos e que sempre existiu por meio da classe trabalhadora, mesmo sem a necessidade de um projeto político popular de reforma agrária, no entanto, a luta pela reforma agrária é intrínseca à luta pela terra, na qual participam diferentes instituições organizacionais.

Pode-se afirmar, assim, que a diferenciação entre luta pela terra e a luta pela reforma agrária é primordial, pois nos auxilia na compreensão de que a primeira acontece sempre independente da segunda. Durante algumas décadas, os camponeses faziam a luta pela terra sem a existência de nenhum projeto de reforma agrária, pois o primeiro projeto de reforma agrária brasileiro é da década de 1960, denominado de Estatuto da Terra, criado no início da ditadura militar e que ficou apenas no papel.

É indiscutível que a luta por reforma agrária é uma luta muito mais ampla e que envolve toda a sociedade e organizações sociais e sindicais, já a luta pela terra é específica e ampla. Isso nos ajuda a compreender que ainda não foi implantado de fato um projeto político popular de reforma agrária no Brasil, mas está sendo promovida uma intensificação de resistência da luta pelo acesso à terra, por meio das ocupações massivas, realizadas por diversos movimentos sociais e, em especial, o MST, pois as conquistas no aumento do número de assentamentos, só foram possíveis devido à essas lutas e ocupações por parte da classe trabalhadora camponesa. 
Ao longo do processo histórico de luta e resistência dos movimentos sociais do campo foram implantados programas de reforma agrária atrelados à cultura, produção, educação, saúde, políticas agrícolas e infraestrutura social.

Portanto, a luta dos movimentos sociais do campo pelo direito à terra como meio de produção é ampla e perpassa por vários setores da sociedade, pois, também é, sobretudo, uma luta política de um projeto popular de democratização de acesso à terra e redistribuição de renda. Assim, Lênin (1977, p. 428) ressalta que "os camponeses compreendem vagamente o que necessitam, mas não sabem vincular seus desejos e reivindicações ao regime político geral"; existe, assim, a necessidade da politização e união dos camponeses com os operários por meio da coletividade.

\section{A QUESTÃO AGRÁRIA NO BRASIL}

Ao tratarmos acerca das ocupações de terra, da reforma agrária e da questão agrária, notamos que tudo está ligado à terra e que nunca houve de fato um processo de reforma agrária no Brasil, pois a concentração da propriedade privada da terra tem aumentado a cada ano com a acumulação do capital pela classe dominante, que detém os meios de produção, criminaliza os movimentos sociais e utiliza do aparelho repressivo do Estado para reprimir as ocupações de terra.

Desde o período Brasil-Colônia, terra é sinônimo de poder, de riqueza e de disputa por território. Apesar de existirem muitas formas de controle da terra, sem dúvida, a propriedade privada é a dominante e com a Lei de Terras de 1850, a propriedade privada foi instituída no Brasil. Segundo Alentejano (2012), nem todos podiam comprar um pedaço de terra, passando, assim, a ser tratada como uma mercadoria que abriu margens para a grilagem, a falsificação de documentos e o aumento da exclusão social.

Contudo, existem no Brasil outras formas de acesso à terra e não apenas por meio da propriedade privada; existem terras que são ocupadas há tempos por comunidades rurais, indígenas e quilombolas que as utilizam para o extrativismo, a agricultura e a pecuária, mas que não possuem a propriedade legal. As grandes extensões de terras do latifúndio, que não cumprem a sua função social da propriedade e que estão, em sua maior parte, improdutivas, acabam sendo desapropriadas pelo Estado e destinadas a assentamentos rurais para reforma agrária, sob o controle do Instituto Nacional de Colonização e Reforma Agrária (INCRA). 
Segundo Sampaio Jr. (2013, p. 206-207),

O Brasil desperdiçou todas as oportunidades históricas de encaminhar uma solução construtiva para a questão agrária. No momento da independência, a liderança da aristocracia agrária acarretou na revitalização dos dois pilares fundamentais da economia colonial: o monopólio da terra pelos grandes latifundiários e a continuidade do trabalho escravo. $\mathrm{Na}$ abolição, as classes dominantes tiveram a preocupação explícita de preservar a assimetria da sociedade colonial, evitando, com a Lei de Terras de 1850, que os recém-libertos e os imigrantes pobres tivessem livre acesso à propriedade da terra.

A propriedade privada da terra foi consolidada a partir da Revolução Industrial, por meio de normas institucionais estabelecidas pelo Estado burguês, que permitiu a acumulação do capital por parte da classe dominante, que passaria a deter os meios de produção. Assim, com base em Stédile (2012), o termo questão agrária trata especificamente do uso, da posse e da propriedade da terra em uma determinada sociedade, ao longo do processo histórico, além de analisar as formas de produção e de produtos agrícolas cultivados em certas regiões.

No Brasil, de 1961-1964, foi proposto um modelo de Reforma Agrária Clássica para tentar solucionar os problemas agrários da sociedade durante o processo histórico de organização e produção no campo.

Durante o Governo de João Goulart (1961-1964), segundo Stédile (2012), foi proposto um modelo de Reforma Agrária Clássica no Brasil, defendida pela Comissão Econômica das Nações Unidas para a América Latina (CEPAL), na tentativa de solucionar o problema da questão agrária brasileira, mas, logo após o envio do projeto de lei ao Congresso, o governo de Jango foi derrubado pelo golpe de estado e seguimos vinte anos de regime militar, que priorizou apenas programas de colonização e redistribuição de terras públicas, passando a beneficiar fazendeiros e empresas multinacionais do mercado financeiro.

Os governos militares promoveram a desconstrução da reforma agrária, reprimiram os movimentos sociais e implantaram um modelo de desenvolvimento agrário para atender os interesses da classe dominante burguesa, ao apostarem no fim do campesinato. Como aborda Tardin (2012, p. 178):

A ditadura militar instalada no país em 1964 impôs a RevoluçãoVerde que implica a utilização de todo um aparato industrial, financeiro, científico, tecnológico, educacional, agroindustrial e comercial por meio de ações do Estado e do capital privado, configurando um 
poderoso sistema e um bloco de poder burguês que invade amplos territórios camponeses, impondo-lhes a modernização conservadora e a condição de subalternidade, seja como "produtores menores" de alimentos e de determinadas matérias-primas, seja como trabalhadores semiassalariados ou assalariados em processos produtivos agrícolas e agroindustriais.

A partir de 1984, foi retomado o regime democrático e houve o ressurgimento dos movimentos sociais camponeses, porém desprovido de uma representatividade efetiva de força política social para implementar um projeto político nacional massivo de reforma agrária popular. Por isso, de acordo Stédile (2012), no Brasil, utilizamos a expressão reforma agrária para designar a desapropriação de fazendas para assentamentos rurais.

Em 1985, foi apresentado à sociedade brasileira um Plano Nacional de Reforma Agrária (PNRA), que não conseguiu cumprir em quatro anos nem 10\% do previsto e só ocorreram algumas desapropriações para assentamentos rurais, porque os sem-terras intensificaram as lutas por ocupações no campo. Em consequência disso, surgiu a União Democrática Ruralista (UDR) dos latifundiários, com o objetivo de defender os privilégios e interesses dos grandes fazendeiros proprietários de terra (FERNANDES, 2012).

O cenário nacional atravessava um momento difícil, pois de um lado estavam os movimentos que aprovavam imediatamente, a aplicação do PNRA, por meio das ocupações de terras improdutivas, e do outro, os que defendiam os interesses dos grandes latifundiários, que, para manterem a posse da terra, radicalizavam qualquer processo de mudança horizontal; além disso, a implantação do plano exigiria uma ação conjunta do Governo Federal, assim como dos Governos Estaduais e Municipais.

A redemocratização do país e a elaboração da Nova Constituição Federal, em 1988, fizeram com que a União Democrática Ruralista (UDR) conseguisse vetar a lei de Reforma Agrária proposta na Constituinte, o que inviabilizou a solução para a questão agrária no Brasil. Como ressalta Sampaio Jr. (2013, p. 210), a "reforma agrária e reforma urbana tornaram-se duas faces de um mesmo processo de transformação social que envolve todas as dimensões da sociedade - a revolução brasileira”.

Com o início da política neoliberal, do governo Fernando Collor de Mello (1990-1992) e seguida por Fernando Henrique Cardoso (1995-2003), as tensões, mobilizações e ocupações de terra no campo aumentaram em todo o país, o que levou à ampla divulgação, através dos meios de comunicação, a buscar construir uma imagem 
ideológica positiva do governo de Fernando Henrique e negativa dos movimentos sociais do campo. A partir de então, segundo Stédile (2012), a questão agrária brasileira passa a ser vista por dois enfoques básicos: o primeiro, defendido por alguns pesquisadores que se juntam a uma visão burguesa da agricultura, e o segundo de uma visão crítica marxista.

O desenvolvimento do campo no Brasil esteve há séculos, relacionado aos padrões da produção capitalista dominante; frente a essa situação de desigualdade social, a luta pela terra é também a luta pela soberania alimentar, para que as pessoas possam produzir seus próprios alimentos mais saudáveis e livres de agrotóxicos. Como destaca Marques (2008, p. 63), “a luta pela Reforma Agrária no Brasil passa pela afirmação de um projeto camponês e tem possibilitado a trabalhadores antes proletarizados ou não a experiência de um modelo de vida camponês e sua conformação enquanto classe" trabalhadora.

Com a eleição de Fernando Henrique Cardoso e a ampliação da política neoliberal, segundo Fernandes (2001), a partir de 1994 a reforma agrária passa a ser vista como uma política compensatória do Governo Federal para a implantação de assentamentos rurais com poucos investimentos em políticas públicas voltadas ao campo. Com a criação do Banco da Terra, em 1998, a política de redistribuição de terra fica a cargo do capital e do mercado, quando ao mesmo tempo se busca reprimir as lutas históricas dos movimentos sociais do campo.

A partir de 1996, o Banco Mundial passa a oferecer um programa de crédito fundiário denominado de Reforma Agrária de Mercado (RAM), alegando que o modelo fundiário brasileiro era conflituoso e caro, mas, como ressalta Trindade (2015, p. 85), “as políticas de Reforma Agrária de Mercado sob orientação do Banco Mundial têm como objetivo a diminuição da pressão social e da ascensão política dos movimentos sociais, além de combatê-los ideologicamente, propondo um acesso à terra sem conflitos".

Além disso, todas as organizações sindicais e movimentos sociais nacionais de representação da classe trabalhadora foram contra a criação do Banco da Terra, mas, mesmo assim, o governo federal acionou a sua base parlamentar majoritária no Congresso Nacional para aprová-lo, usando como argumento que o programa contaria com empréstimos do Banco Mundial ao incorporar o setor empresarial e a direita sindical para gerir o Modelo de Reforma Agrária de Mercado (MRAM) e fazer o embate político contra os movimentos sociais (PEREIRA, 2013). 
A reforma agrária defendida pelos movimentos sociais do campo, articulados primeiramente pela Via Campesina, e depois pelo Movimento dos Trabalhadores Rurais Sem Terra (MST), pela Comissão Pastoral da Terra (CPT), pelo Movimento dos Pequenos Agricultores (MPA), pelo Movimento de Mulheres Camponesas (MMC) e outros movimentos de luta pela democratização de acesso à terra, propõe uma Reforma Agrária Popular similar às que foram aplicadas em outros países da Ásia e Europa.

Sendo assim, Stédile (2012) afirma ser necessário um amplo processo de desapropriação das grandes propriedades privadas pelo governo ao estabelecer um limite máximo para propriedade rural no país, a fim de que a redistribuição de terras seja acompanhada da instalação de cooperativas e formas mais agroecológicas de cultivo da terra, tentando eliminar a estrutura latifundiária na realidade da questão agrária brasileira.

O Modelo de Reforma Agrária de Mercado trouxe retrocessos para a implantação da reforma agrária popular, ao tentar desmontar o projeto dos sem-terras e beneficiar os grandes latifundiários, que passavam a receber dinheiro pela terra, enquanto os camponeses contraiam dívidas. A questão agrária no Brasil, passa a ser vista com esperança a partir de 2003, com o início dos governos neodesenvolvimentistas de Luís Inácio Lula da Silva (2003-2011) e Dilma Vana Rousseff (2011-2016), que no primeiro mandato passa a elaborar o II Plano Nacional de Reforma Agrária, sob fortes mobilizações dos movimentos sociais e sindicais.

Além disso, no que tange os Governos de Lula e Dilma, houve avanços significativos na política de Educação do Campo, como será mostrado mais adiante, mas, no projeto de reforma agrária, não houve mudanças estruturais profundas, tendo em vista que mesmo um governo neodesenvolvimentista não conseguiu romper, em definitivo, com o projeto político neoliberal, pois a classe do capital dominante não tem nenhum interesse em universalizar direitos ao defender um modo de produção de mercado aliado ao agronegócio, que transforma tudo no campo em mercadoria.

O ponto principal do governo Dilma foi o combate à pobreza e à miséria. "Nós precisamos urgentemente construir um novo modelo agrícola baseado em outras diretrizes e na busca constante de uma sociedade mais justa e igualitária, que produza suas necessidades em equilíbrio com o meio ambiente" (BRASIL, 2013, p. 141). Todavia, não se pode pensar em combater a pobreza no campo sem uma reforma agrária popular que possibilite a redistribuição de terras.

A luta dos movimentos sociais do campo por uma reforma agrária popular se faz 
necessária em caráter urgente para além de aspectos macroeconômicos, pois a questão agrária vai além da posse e da propriedade da terra. Por ser maior do que os conflitos de classes sociais, envolve não apenas a redistribuição de terra, mas também as relações de transformação de trabalho, de justiça social e poder no campo. Assim, as políticas de reforma agrária implantadas, na maioria das vezes, foram apenas para aliviar tensões sociais e manter a dependência da classe trabalhadora.

Nesse sentido, a reforma agrária precisa ser feita, segundo Sampaio (2013, p. 94), "porque a concentração da propriedade da terra está na base do sistema de dominação cuja cúpula são os grandes agroindustriais", que detêm os meios de produção.

Assim, para erradicar a pobreza e amenizar os problemas acerca da questão agrária, é necessária a implantação de um projeto popular de desenvolvimento político e socioeconômico focado na agricultura camponesa familiar que vá de encontro à lógica do agronegócio para que possa garantir a soberania alimentar e a cidadania dos camponeses, sendo a questão agrária um desafio permanente que terá de enfrentar a grande estrutura política fundiária brasileira.

\section{A LUTA DOS MOVIMENTOS SOCIAIS EM PROL DA GARANTIA DE DIREITOS: REFLEXÕES SOBRE A EDUCAÇÃO DO CAMPO}

Os movimentos sociais buscam, assim, expressar as demandas e interesses da classe trabalhadora por meio das ações sociais coletivas de caráter sociopolítico e cultural para reivindicar direitos de uma determinada classe ou categoria. As lutas por liberdade sempre estiveram atreladas à terra e à exploração dela através da utilização da força de trabalho escrava, indígena e de imigrantes pobres subordinados aos interesses capitalistas. Assim, surge a primeira rebelião indígena contra o cativeiro e pela liberdade, entre 1554 e 1567, além da resistência à dominação aos movimentos que deram início a várias outras rebeliões pelo Brasil.

Os movimentos sociais do campo de acordo Guzmàn e Molina ${ }^{1}$ (2005), são aqueles movimentos constituídos pelos trabalhadores rurais que envolvem principalmente o campesinato e surgem a partir de duas principais frentes de luta: as Ligas Camponesas, entre 1940 e 1960, e o Movimento dos Trabalhadores Rurais Sem

\footnotetext{
${ }^{1}$ Ver GUZMÀN, Sevilla Eduardo; MOLINA Manoel González. Sobre a evolução do conceito de campesinato.
} Trad. Ênio Guterres e Horário Martins de Carvalho. 3. Ed. São Paulo: Expressão Popular, 2005. 
Terra (MST), criado em 1984, que tinham como bandeiras de luta a reforma agrária, as melhorias nas condições de vida da classe trabalhadora camponesa, o direito ao acesso à educação e que atendessem às especificidades da comunidade campesina e combatessem a lógica dominante de substituição do homem pela máquina, por meio do agronegócio.

A proposta educacional do MST se baseia em quatro correntes epistemológicas distintas, sendo: a Educação Popular almejada por Paulo Freire, que tinha como princípio a liberdade e igualdade humana; a Pedagogia Socialista, por meio das experiências de luta social e política dos movimentos sociais; a Pedagogia em Movimento, difundida pelo MST em sua dinâmica histórica de luta e a Educação do Campo, que surge dentro dos movimentos sociais do campo por direito à terra e à educação.

Muito se discute acerca da importância do MST em prol da luta por igualdade e direitos sociais; mas o que motiva as pessoas a lutarem e se organizarem em grupos e movimentos sociais? Desde o período de colonização, até a contemporaneidade, a sociedade brasileira é marcada por lutas, conflitos e mobilizações contra a dominação do território, a escravidão, a exploração econômica e, mais recentemente, contra a exclusão social, a expropriação e a retirada de diretos sociais da classe trabalhadora.

O período do regime populista da Era Vargas foi um momento simbólico em termos de lutas sociais e conquistas para a classe trabalhadora, alinhada a um cenário internacional de desenvolvimento e da conjuntura de redemocratização do país mesmo sob tensão da Guerra Fria. Mas, no início da década de 1960, e com o Golpe em 1964, eclodiram centenas de greves por todo o país e foram proibidas as manifestações, além de serem cassados e punidos os manifestantes por meio do Ato Institucional $\mathrm{N}^{\mathrm{o}} 5$, durante o Regime Militar.

Em 1974, com a crise do petróleo, começa a se articular certa resistência ao Regime Militar; os movimentos sociais começam a renascer das cinzas e voltam a se organizar por todo o país, surgindo, assim, na área da educação, o Movimento de Educação de Base (MEB), além de outros movimentos sociais precursores que conhecemos hoje, como a Central Única dos Trabalhadores (CUT) e o MST, pois como ressalta Carvalho (2003, p. 25):

O golpe militar não só trouxe a "modernização conservadora" para o campo, como violência, militarização, expansão dos conflitos e êxodo rural. Trouxe também sua contradição: a luta por condições de vida e a 
necessidade de alfabetizar os trabalhadores do campo. Neste embate histórico, cresce o Movimento de Educação de Base, cresce a consciência política dos trabalhadores organizada em torno de matrizes teóricas libertadoras. Constituíram equipes de educação popular para alfabetização, segundo método Paulo Freire. Esses núcleos educacionais serviram principalmente para formação de coletividades autoorganizadas.

Ainda, no que tange às lutas dos movimentos sociais do campo e do MST durante o seu processo histórico de formação, são visíveis a violência e repreensão aos indígenas, quilombolas, camponeses e ribeirinhos que não se submeteram à lógica capitalista do latifúndio e passaram a lutar por direito à democratização de acesso à terra. É importante destacar que os movimentos sociais não são apenas sujeitos de luta, mas, também, de formação e politização que contribuem de forma determinante, por meio das pressões e mobilizações de massa, por mais direitos sociais.

Nesse sentido, destaco a luta dos movimentos sociais do campo por uma educação voltada a atender as especificidades das famílias camponesas e que possibilite o desenvolvimento da comunidade campesina como um todo. A sociedade está aprendendo com os movimentos sociais do campo ao buscar uma modalidade educativa voltada à classe trabalhadora camponesa.

Dessa maneira, compreendemos que o movimento social é educativo em si mesmo, representa uma nova consciência de luta da classe trabalhadora por direito ao acesso à terra, à justiça, à igualdade, à saúde e à educação. Assim, a Educação do Campo, segundo Santos (2016, p. 165)

Nasceu das lutas da classe trabalhadora camponesa organizada, principalmente, como movimentos sociais que buscam um projeto educacional na forma de política que respeite os interesses dos diversos sujeitos coletivos, que fazem do campo o seu território de vida. Esse projeto vem se concretizando formalmente a partir da correlação de forças sem disputa na sociedade, quais sejam: a classe trabalhadora e o agronegócio.

Apesar dos avanços e conquistas na Educação do Campo, ainda há muitos desafios postos às escolas e aos movimentos sociais, sendo necessários, além da formação de professores/professoras voltada à essa modalidade de ensino; também a oferta de livros didáticos adequados aos anos iniciais do Ensino Fundamental, além de apoio às escolas quilombolas, indígenas e ribeirinhas.

Nessa perspectiva, tem-se como alternativa, a implementação de cursos de 
formação inicial e continuada para os professores, como licenciaturas em Educação do Campo, Educação Quilombola, Educação Indígena, além de cursos de extensão, aperfeiçoamento e especialização específica para os profissionais que atuam ou irão atuar nas escolas do campo. Tais escolas precisam levar em consideração as lutas e histórias de vida de cada educando, já que é na diversidade coletiva que se possibilita a troca de experiências e de conhecimento de cada um para se pensar na construção de um projeto popular de desenvolvimento educacional, que não apenas seja teórico, mas também prático e vinculado ao mundo do trabalho, da cultura, da terra e da produção.

Desse modo, a escola se vincula não a seu processo formativo cultural, mas também de produção e social, pois não é apenas na escola que se pode educar a criança, como prevê o $1^{\circ}$ artigo da Lei de Diretrizes e Bases da Educação (LDB nº 9.394/1996), “A educação abrange os processos formativos que se desenvolvem na vida familiar, na convivência humana, no trabalho, nas instituições de ensino e pesquisa, nos movimentos sociais e organizações da sociedade civil e nas manifestações culturais" e, ainda acrescenta, "A educação escolar deverá vincular-se ao mundo do trabalho e à prática social".

Observa-se o grande desafio dos movimentos sociais do campo ao lutarem por uma educação e escola do e no campo, que levem em consideração as mudanças sociais, políticas, econômicas e tecnológicas da atualidade, que visem o saber universal e às experiências de vida dos camponeses, para que formem sujeitos cada vez mais participativos e atuantes na sociedade.

Ainda, convém lembrar que é preciso superar a visão arcaica de que o campo é lugar de atraso e retrocesso, afinal, há mais vida no chão do campo do que no concreto do chão da cidade, e o movimento social mostra como isso incomoda ao colocar-se em movimento e em ação na luta por direitos da classe trabalhadora.

A Educação do Campo nasce, assim, a partir da pressão/mobilização por parte dos movimentos sociais e sindicais do campo em oposição ao sistema capitalista, que, além de explorar, aumenta cada vez mais a desigualdade social no campo. Segundo Caldart (2007, p. 3), "os sujeitos que trabalham e vivem do campo e seus processos de formação pelo trabalho, pela produção de cultura, pelas lutas sociais, não têm entrado como parâmetros na construção da teoria pedagógica e muitas vezes são tratados de modo preconceituoso, discriminatório".

Nesse sentido, a luta dos movimentos sociais do campo na atualidade é priorizar o acesso à educação como necessidade básica dos trabalhadores rurais e mudar a 
concepção de que o campo é lugar de atraso, que serve apenas para prover o mercado econômico. Assim, deve-se procurar construir um projeto popular de educação libertadora do campo que incorpore a cultura, a produção e o conhecimento voltados à reflexão acerca do trabalho camponês e das lutas dos movimentos sociais e sindicais para garantir condições de direito e sobrevivência da classe trabalhadora.

\title{
EDUCAÇÃO DO CAMPO: CONQUISTAS, DESAFIOS E RETROCESSOS
}

No século XXI, após décadas de lutas, os povos do campo, junto aos movimentos sociais do campo, enfrentaram diversos processos políticos que tentaram derrubar o movimento camponês, especialmente por parte da bancada ruralista e da mídia, que tentam passar uma imagem subversiva e equivocada dos movimentos sociais. Assim, a luta dos trabalhadores rurais sem terra por melhores condições de vida é constante, não apenas por mais assentamentos e reforma agrária, mas, para além da terra, por condições de acesso a direitos sociais. De acordo com Carvalho (2013, p. 139-140),

\begin{abstract}
Não será suficiente a articulação política entre movimentos e organizações sociais e sindicais populares do campo e da cidade para romper com a hegemonia capitalista e, em particular, alterar a estrutura fundiária do país se esses movimentos e organizações não forem portadores de uma nova concepção de sociedade para o campo e, como sugestão, não contemplarem nas suas concepções a possibilidade de uma "reapropriação social da natureza" capaz não apenas de negar a apropriação privada da natureza pelo capital, mas de instaurar o poder popular para a reinvenção e emancipação das multiterritorialidades rurais.
\end{abstract}

Nessa perspectiva, as proposições de mudanças almejadas pelos movimentos sociais do campo brasileiro dependem, constantemente, de um processo de luta e resistência, além da conscientização política coletiva por parte da classe trabalhadora, tanto do campo, como das cidades para que, em ação conjunta, possam unir forças suficientes para estabelecer mudanças concretas e combater as investidas do agronegócio no campo. São mudanças que as elites burguesas oposicionistas à reforma agrária popular jamais aceitarão, pois isso acabaria extinguindo seus mecanismos de opressão, mão de obra barata, exploração e acumulação de terra e capital, tendo em vista que as transformações concretas só acontecerão por meio da pressão e mobilização popular. 
A formação dos sujeitos do campo é essencial para a politização da luta de classe organizada, sendo por meio da educação que os trabalhadores camponeses poderão construir um projeto educacional e de reforma agrária popular emancipatória que respeite os princípios dos sujeitos coletivos e que faça do campo seu espaço de trabalho e moradia; assim, buscarão mecanismos de superação do eclipse ideológico imposto pelo sistema capitalista agrário.

As conquistas recentes acerca da construção dos Marcos Políticos e Legais da Política Nacional de Educação do Campo foram originadas das intensas lutas e mobilizações dos movimentos sociais e sindicais em defesa de um projeto educativo popular que possa estabelecer vínculos com a produção, a cultura e os saberes populares dos camponeses, agricultores familiares, lavradores, indígenas, quilombolas, pescadores, ribeirinhos, atingidos por barragens, assentados da reforma agrária e demais povos que habitam e vivem no campo ao buscar, assim, superar o modelo de educação rural atrelado ao princípio da hegemonia burguesa.

Nesse sentido, a proposta de políticas públicas de educação voltada para a população do campo necessita superar a lógica dominante, por meio da luta contrahegemônica para que assim possa extrapolar as paredes da escola por meio da luta de classe organizada em defesa do acesso à terra, à cidadania, ao trabalho e a educação. Segundo Capanema (2004, p. 41), "só a educação pode dar conta desta assimetria no desenvolvimento social e econômico das sociedades, realizando a compatibilização entre crescimento econômico e justiça social" na vida dos camponeses, por meio da igualdade de participação política e em defesa da vida humana e do meio ambiente.

Nessa perspectiva, convém ratificar que a educação é um direito de todos e um dever do Estado, sendo assim, um direito social elementar, previsto na Constituição Federal de 1988, e não está a serviço da lógica de mercado por se tratar de um bem imaterial, cultural e essencial de cada povo ao procurar estabelecer a promoção da igualdade de oportunidades. Assim, é importante compreender o percurso histórico da luta dos movimentos sociais e sindicais em prol da Educação do Campo no Brasil, que ganhou força a partir de 1989, num movimento inicial denominado de "Articulação Nacional por uma Educação do Campo", que reivindicava adequação de práticas pedagógicas que atendessem aos sujeitos do campo (MOLINA; JESUS, 2004).

A partir de muitas mobilizações em defesa da Educação do Campo por todo o país é que surge, nos anos seguintes, segundo Santos (2015), o "Movimento pela Educação do Campo", que unificou as lutas e mobilizações dos diferentes sujeitos do 
campo, entidades sociais e pesquisadores para elaborar uma agenda voltada para o desenvolvimento da política pública de Educação do Campo que possibilitasse o acesso e o direito à educação pública e permanência da escola do/no campo para que, assim, possa fortalecer os projetos de vida das populações do campo.

O marco institucional que consagrou a Educação do Campo como política pública se deu a partir da aprovação das "Diretrizes Operacionais para a Educação do Campo nas Escolas do Campo", em que, conforme Santos (2015), pela primeira vez na história da educação brasileira, foram regulamentadas políticas públicas voltadas especificamente para a educação básica do campo. Segundo Fernandes et al. (2004, p. 136):

\begin{abstract}
A aprovação das Diretrizes representa um importante avanço na construção do Brasil rural, de um campo de vida, onde a escola é espaço essencial para o desenvolvimento humano. Afirma ainda que, esse documento significa um novo passo da caminhada de quem acredita que o campo e a cidade se completam e, por isso mesmo, precisam ser compreendidos como espaços geográficos singulares e plurais, autônomos e interativos, que não podem ser pensados como relação de dependência eterna ou pela visão urbanóide e totalitária.
\end{abstract}

Dessa forma, foi a partir das mobilizações e lutas dos movimentos sociais de massa organizados que foram possíveis a consolidação e a implantação de políticas públicas que (re)colocaram em pauta nacional a discussão sobre a educação do campo, incorporando no debate as lutas, as vivências e a cultura dos camponeses. Além disso, foi criado, em 1998, o Programa Nacional de Educação na Reforma Agrária (PRONERA), com a finalidade de garantir o direito à educação das populações organizadas, como assentados e acampados da reforma agrária, em que, a relação entre educação e o modo de produção no campo parte de uma matriz formativa em que a Pedagogia tem o princípio educativo como constituidor primordial do ser humano.

Olhando no retrovisor da história é visível a força dos movimentos sociais e sindicais do campo para as conquistas alcançadas até aqui, a fim de garantir os direitos dos povos do campo. No entanto, estamos vivenciando momentos desanimadores no contexto atual, tanto na perspectiva das investidas do capital no campo brasileiro, como no que tange às medidas defendidas pelo Governo Temer, tais como: a Reforma Trabalhista, a Proposta de Emenda Constitucional Parlamentar - $\mathrm{n}^{\circ} 55$, de 2016 do teto dos gastos públicos, as Reformas do Ensino Fundamental e Médio, que foram aprovadas sem um amplo debate popular na sociedade. Nesse cenário de retiradas de direitos da classe trabalhadora, a sociedade precisa se posicionar em oposição ao atual 
estágio do capitalismo no campo e na cidade, que transformou a vida em mercadoria.

É necessário dizer que a Consolidação das Leis Trabalhistas (CLT Lei n ${ }^{\circ} 5.452$, de $1^{\circ}$ de maio de 1943) foi uma conquista da luta da classe trabalhadora, que teve como garantia preservar os direitos do empregado, mas, uma recessão econômica no cenário brasileiro atual fez com que o Governo Federal criasse uma Medida Provisória (MP) para desonerar o custo do empregador através da flexibilização por meio de uma Reforma Trabalhista, que vende o discurso de gerar novos empregos no país, manter os que já existem e buscar diminuir o custo gerado por um empregado.

Em contrapartida, um fator preocupante é que a Reforma Trabalhista, além de se tornar prejudicial ao trabalhador, possa aumentar as contratações terceirizadas e precarizar ainda mais as relações de trabalho ao trazer prejuízos aos direitos trabalhistas já conquistados na CLT.

A PEC $n^{\circ} 55$, do teto dos gastos públicos foi mais uma Proposta de Emenda Constitucional do Governo Federal, que foi aprovada com o objetivo de congelar, por 20 anos, gastos na área social, como saúde e educação, que ficarão comprometidas no futuro; além de diminuir recursos de programas sociais como o Bolsa Família, o que impactará, significativamente, a população mais pobre do país, especialmente as pessoas que vivem e trabalham no campo.

Essa PEC é uma proposta ultraneoliberal, conservadora, que prejudica o futuro do desenvolvimento do Brasil. Nenhum outro país do mundo tem uma proposta semelhante de congelar investimentos públicos na área social por duas décadas. $\mathrm{O}$ Governo brasileiro não levou em consideração que a dívida pública cresceu devido as reservas cambiais e a significativa queda da arrecadação, ou seja, o problema não está nos gastos públicos, mas nas receitas públicas.

Além disso, outro fator preocupante foi a aprovação das Reformas do Ensino Fundamental e Médio sem uma ampla consulta popular junto à sociedade civil organizada, nem aos profissionais da educação básica acerca da reforma que altera pontos da LDB/96, propondo, assim, alterações no currículo ao determinar uma Base Nacional Comum Curricular (BNCC) e estimular a formação profissional técnica.

Diante dessas e outras reformas súbitas do Governo, os movimentos sociais, militantes, ativistas e estudantes de todo o país têm resistido, bravamente, às reformas com ocupações de escolas, universidades públicas e manifestações nas ruas para denunciar as reformas impopulares e o futuro incerto do Brasil.

A luta contra-hegemônica não é fácil na conjuntura política e social pela qual 
passa o país, especialmente para os sem-terras e os pequenos camponeses, que são vítimas da exclusão social de políticas públicas voltadas aos sujeitos do campo que possam lhes garantir condições mínimas de vida e permanência no meio rural.

\section{CONSIDERAÇÕES FINAIS}

Neste trabalho, partimos do pressuposto de que a discussão acerca da tríade Questão Agrária, Movimentos Sociais e Educação do Campo deve acontecer de forma interligada, pois a Educação do Campo perpassa pela Questão Agrária brasileira, pela infraestrutura latifundiária patronal e pelo jogo de interesses da classe dominante, tendo os movimentos sociais como sujeitos que vão na contraposição dos interesses da classe dominante.

Nesse sentido, o debate sobre a tríade necessita avançar na perspectiva da superação da visão fragmentadora e discriminatória do campo. Nesse contexto é que se constitui a Educação do Campo que ultrapasse as questões da formação pedagógica, organizativa e ideológica.

Os movimentos sociais inauguram e afirmam, assim, um novo marco na história em defesa da Educação do Campo em disputa por um projeto hegemônico de poder, pois as conquistas se dão a partir do campo de lutas, fruto dos debates e tensões sociais as quais permeiam as populações do campo na defesa da educação, acesso à terra, moradia, saúde, entre outros direitos constitucionalmente conquistados, mas, historicamente negados.

A priori, é necessário vincular a escola do campo a uma concepção de educação que impliquem uma transformação da escola atual e que possibilite uma formação teórico/prática não apenas pedagógica, mas também política, de lutas sociais vinculadas aos objetivos da classe trabalhadora. Além do mais, salientamos que a luta dos movimentos sociais do campo não é apenas por uma Educação do Campo, mas também pela democratização do direito ao acesso à terra, à justiça social, melhores condições de vida no campo e por uma mudança na matriz de produção capitalista agrária por uma matriz mais agroecológica sustentável, que promova a soberania alimentar das populações do campo. Uma produção que valorize a vida e não apenas o capital.

A terra sempre foi e continua sendo um símbolo de dominação e poder. Não é um fruto do trabalho humano, mas sim um bem natural e universal; portanto, não tem valor em si mesma. Todos deveriam ter acesso ao uso e posse da terra se a propriedade 
privada não fosse tão desigual e alienante, ao separar o homem da natureza e do produto do seu trabalho, pois aquilo que o trabalhador produz não lhe pertence, mas a quem controla os meios de produção por meio da compra da sua força de trabalho.

As lutas e mobilizações históricas de resistência no campo brasileiro estão atreladas à terra e à exploração dela pela lógica do capitalismo agrário, na qual os conflitos demarcam a história das classes sociais ao definir privilegiados e marginalizados que criam um sistema de dominação e resistência no campo e na cidade.

Nesse contexto, é preciso pensar numa reforma agrária popular no campo que extrapole a simples divisão de terra e possibilite a participação igualitária de todos, especialmente das mulheres, para eliminação da pobreza e redistribuição de renda, pois, assim, será possível promover igualdade com educação e trabalho no campo, além de garantir a soberania alimentar com a produção de alimentos orgânicos e preservação da biodiversidade dos diferentes biomas de cada região.

Portanto, reafirmamos a importância da luta dos movimentos sociais do campo por reforma agrária, educação e trabalho, bem como a necessidade de um debate profundo e intenso acerca do limite da propriedade privada, do modo de produção agrícola, do modelo de educação a ser ofertado no campo e na cidade, de modo que possamos construir processos mais democráticos de acesso e uso da terra, da produção, da cultura, da educação e de todos os bens da natureza.

\section{REFERÊNCIAS}

ALENTEJANO, Paulo. Terra. In: CALDART, Roseli Salete (org.) et al. Dicionário da Educação do Campo. 2. ed. Rio de Janeiro, São Paulo: Escola Politécnica de Saúde Joaquim Venâncio, 2012, p. 740-743.

BRASIL. Lei de Diretrizes e Bases da Educação Nacional. Lei N ${ }^{\circ}$ 9.394, 20 de dezembro de 1996.

BRASIL. Via Campesina. Plataforma de política para a agricultura brasileira. In: STEDILE, João Pedro (Org.). A questão agrária do Brasil: debate sobre a situação e perspectivas da reforma agrária na década de 2000. São Paulo: Expressão Popular, 2013, p. 127-140.

CALDART, Roseli Salete. Movimento sem terra: lições de pedagogia. Currículo sem Fronteiras. Disponível em: http://www.currilosemfronteiras.org/articicles.htm2006. Acesso em: 24/01/2018.

Sobre Educação do Campo. In: III Seminário do Programa Nacional de Educação na Reforma Agrária (PRONERA), Luziânia, GO, 2007.

CAPANEMA, Clélia de Freitas. Gênese das mudanças nas políticas públicas e na gestão da educação básica. In: BITTAR, Marluce; et al. (Org.). Gestão e políticas da 
Educação. Rio de Janeiro: DP\&A, 2004.

CARVALHO, Horácio Martins de. Uma ressignificação para a reforma agrária no Brasil. In: STÉDILE, João Pedro (Org.). A questão agrária do Brasil: debate sobre a situação e perspectivas da reforma agrária na década de 2000. São Paulo: Expressão Popular, 2013, p. 127-140.

CARVAlHO, Marize Souza. Formação de Professores e Demandas dos Movimentos Sociais: A Universidade Necessária. Dissertação de Mestrado, Universidade Federal da Bahia, Faculdade de Educação, Programa de Pós-Graduação em Educação. Salvador, Bahia, 2003.

DESMARAIS, Anette Aurélie. A Via Campesina: a globalização e o poder do campesinato. Trad. Carlos Alberto Silveira Betto Soares. São Paulo: Cultura Acadêmica: Expressão Popular, 2013.

FERNANDES, Bernardo Mançano. A formação do MST no Brasil. Petrópolis, RJ: Vozes, 2000.

Brasil: 500 anos de luta pela terra. Revista de Cultura Vozes, mar., 2001. Disponível em: www.culturavozes.com.br/revistas/0293.html. Acesso em: 24/01/2018.

Movimento dos Trabalhadores Rurais Sem Terra (MST). In: CALDART, Roseli Salete (Org.) et al. Dicionário da Educação do Campo. 2. ed. Rio de Janeiro, São Paulo: Escola Politécnica de Saúde Joaquim Venâncio, 2012, p. 496-499.

. Questão agrária, pesquisa e MST. São Paulo: Cortez, 2001.

; CERIOLI, Paulo Ricardo; CALDART, Roseli Salete. Primeira Conferência Nacional. Por uma educação básica do campo: texto preparatório. In: Mônica Castagna (Org.). Por uma Educação do Campo. Petrópolis: Vozes, 2004.

GOHN, Maria da Glória. Novas teorias dos movimentos sociais. 2. ed. São Paulo: Loyola, 2008.

GUZMÀN, Sevilla Eduardo; MOLINA Manoel González. Sobre a evolução do conceito de campesinato. Trad. Ênio Guterres e Horário Martins de Carvalho. 3. Ed. São Paulo: Expressão Popular, 2005.

LÊNIN, Vladimir Ilyich. O Estado e a Revolução: O que ensina o marxismo sobre o Estado e o papel do proletariado na Revolução. São Paulo: Hucitec, 1977.

MARQUES, Marta Inez Medeiros. Agricultura e campesinato no mundo e no Brasil: um renovado desafio à reflexão teórica. In: PAULINO, Eliane Tomiasi; FABRINI, João Edmilson (Org..). Campesinato e territórios em disputas. São Paulo: Expressão Popular, UNESP, Programa de Pós-graduação em Geografia, 2008, p. 49-78.

MELUCCI, Alberto. Um objetivo para os Movimentos Sociais? In: Lua Nova: Revista de Cultura e Política. No 17, junho de 1989, p. 51-66. Tradução de Suely Bastos.

MOLINA, Mônica Castagna; JESUS, Sônia Meire Santos Azevedo de (orgs.). Contribuições para a construção de um projeto de Educação do Campo. Coleção por uma Educação do Campo, $n^{\circ}$ 5. Brasília: Articulação Nacional Por uma Educação do Campo, 2004.

MOVIMENTO DOS TRABALHADORES RURAIS SEM TERRA (MST). Educação no MST:balanço 20 anos. Boletim da Educação, São Paulo, nº 9, 2004.

PEREIRA, João Márcio Mendes. A luta política em torno da implementação do modelo de reforma agrária de mercado durante o governo Cardoso. In: STEDILE, João Pedro (Org.). A questão agrária do Brasil: debate sobre a situação e perspectivas da reforma 
agrária na década de 2000. São Paulo: Expressão Popular, 2013, p. 19-68.

SAMPAIO JR., Plínio de Arruda. Notas críticas sobre a atualidade e os desafios da questão agrária. In: STEDILE, João Pedro (Org.). A questão agrária do Brasil: debate sobre a situação e perspectivas da reforma agrária na década de 2000. São Paulo: Expressão Popular, 2013, p. 167-187.

SAMPAIO, Plínio de Arruda. A questão agrária brasileira e a luta pelo socialismo. In: STEDILE, João Pedro (Org.). A questão agrária do Brasil: debate sobre a situação e perspectivas da reforma agrária na década de 2000. São Paulo: Expressão Popular, 2013, p. 85-102.

SANTOS, Arlete Ramos dos. Aliança (neo)desenvolvimentista e decadência ideológica no campo: movimentos sociais e reforma agrária do consenso. Curitiba: CRV, 2016, 210 p.

SANTOS, Givandete Evangelista dos. A Gestão da Política da Educação do Campo na Bahia. 122 f. Dissertação (Mestrado) - Programa de Pós-Graduação Profissional em Gestão e Avaliação, Universidade Federal de Juiz de Fora, 2015.

SILVA, Maria Lucia Carvalho da. Movimentos Sociais: gênese e principais enfoques conceituais. In: Revista Kairos. São Paulo, 2001.

STÉDILE, João Pedro. Questão Agrária. In: CALDART, Roseli Salete (Org.) et al. Dicionário da Educação do Campo. 2. ed. Rio de Janeiro, São Paulo: Escola Politécnica de Saúde Joaquim Venâncio, 2012, p. 639-644.

TARDIN, José Maria. CULTURA CAMPONESA. In: CALDART, Roseli Salete (Org.) et al. Dicionário da Educação do Campo. 2. ed. Rio de Janeiro, São Paulo: Escola Politécnica de Saúde Joaquim Venâncio, 2012, p. 178-186.

TRINDADE, Domingos Rodrigues da. Constituição social do ser jovem camponês no contexto de assentamentos da Reforma Agrária na microrregião de Guanambi. 2015. 356 f. Tese (doutorado) - Programa de Pós-graduação em Educação, Universidade de Brasília, DF, 2015. 